\section{Temperature and Photoperiod Regulate Flowering of Potted Miltoniopsis Orchids}

\author{
Roberto G. Lopez ${ }^{1}$ and Erik S. Runkle ${ }^{2}$ \\ Department of Horticulture, Michigan State University, East Lansing, MI 48824
}

Additional index words. pansy orchid, short days, vernalization

\begin{abstract}
Miltoniopsis orchids have appealing potted-plant characteristics, including large, fragrant, and showy pansylike flowers that range from white and yellow to shades of red and purple. Scheduling orchid hybrids to flower on specific dates requires knowledge of how light and temperature regulate the flowering process. We performed experiments to determine whether a 9- or 16-h photoperiod [short day (SD) or long day (LD)] before vernalization and vernalization temperatures of $8,11,14,17,20$, or $23{ }^{\circ} \mathrm{C}$ under SD or LD regulate flowering of potted Miltoniopsis orchids. Flowering of Miltoniopsis Augres 'Trinity' was promoted most when plants were exposed to SD and then vernalized at 11 or $14^{\circ} \mathrm{C}$. Additional experiments were performed to determine how durations of prevernalization SD and vernalization at $14^{\circ} \mathrm{C}$ influenced flowering of Miltoniopsis Augres 'Trinity' and Eastern Bay 'Russian'. Plants were placed under SD or $\mathrm{LD}$ at $20^{\circ} \mathrm{C}$ for $\mathbf{0}$, $4,8,12$, or 16 weeks and then transferred to $14^{\circ} \mathrm{C}$ under SD for 8 weeks. Another set of plants was placed under SD or $\mathrm{LD}$ at $20^{\circ} \mathrm{C}$ for 8 weeks and then transferred to $14^{\circ} \mathrm{C}$ with SD for $0,3,6,9$, or 12 weeks. After treatments, plants were grown in a common environment at $20{ }^{\circ} \mathrm{C}$ with LD. Flowering of Miltoniopsis Augres 'Trinity' was most complete and uniform ( $\geq 90 \%)$ when plants were exposed to SD for 4 or 8 weeks before 8 weeks of vernalization at $14^{\circ} \mathrm{C}$. Flowering percentage of Miltoniopsis Eastern Bay 'Russian' was $\geq \mathbf{8 0}$ regardless of prevernalization photoperiod or duration. This information could be used by greenhouse growers and orchid hobbyists to more reliably induce flowering of potted Miltoniopsis orchids.
\end{abstract}

Flowering potted orchids have become one of the largest segments of floriculture worldwide. In the United States, orchids are the second most valuable flowering potted crop, with a reported wholesale value of $\$ 128$ million in 2004 (U.S. Department of Agriculture, 2005). It is estimated that $85 \%$ to $90 \%$ of all orchids sold in the United States are Phalaenopsis, or the moth orchid (Nash, 2003). As the commercial market becomes saturated with Phalaenopsis because of the widespread knowledge of its flower-induction requirements, the sales price will likely decrease and it may become a commodity. Consequently, commercial growers and retailers are seeking other potted flowering orchids that have consumer appeal and can be programmed to flower for specific markets dates.

Miltoniopsis, or the pansy orchid, produces inflorescences with three to seven flat and large (7 to $8 \mathrm{~cm}$ ), fragrant and showy flowers, which range from white and yellow to shades of red and purple. The flowers can last on the plant

Received for publication 3 Feb. 2006. Accepted for publication 27 Feb. 2006. We gratefully acknowledge funding by Michigan's plant agriculture initiative at Michigan State University (Project GREEEN), the Michigan Agricultural Experiment Station, the Fred C. Gloeckner Foundation, and greenhouse growers providing support for Michigan State University floriculture research. We also thank Donald Garling for his contributions to this manuscript. ${ }^{1}$ Graduate student.

${ }^{2}$ Assistant professor and extension specialist, to whom reprint requests should be addressed; e-mail runkleer@msu.edu. for 4 to 8 weeks at 14 to $20{ }^{\circ} \mathrm{C}$ (Baker and Baker, 1993; Robinson, 2002).

In its native habitat, Miltoniopsis is an epiphytic and lithophytic genus of six species distributed from humid lowlands to relatively cool and wet cloud forest regions (50 to 2,100 m) ofColombia, Costa Rica, Ecuador, Panama, Peru, and Venezuela (Baker and Baker, 1993; Morrison, 2000; Lopez and Runkle, 2005). The day temperature in their native forest canopies rarely exceeds $27^{\circ} \mathrm{C}$, and the night temperature may drop to $10^{\circ} \mathrm{C}$ or lower (Sweet, 1978). The sympodial growth habit of this compact plant is distinguished from Miltonia by the presence of a single leaf at the apex of the pseudobulb, which is surrounded by distinct leaflike sheaths. Several outstanding Miltoniopsis hybrids have been developed in recent years and are primarily grown by orchid hobbyists.

Miltoniopsis has become the fourth most valuable potted orchid produced commercially in the Netherlands, with 797,000 pots sold in 2001 (Barendse, 2002). The demand for Miltoniopsis orchids in the United States is greatest during December and February for the Christmas and Valentine's Day holidays. In an online survey of potted orchid buyers in the midwestern U.S., participants between the ages of 20 and 62 years selected Miltoniopsis as their most preferred species among Brassia, Degarmoara, and Phalaenopsis (Behe et al., 2003). Participants had the highest average purchase intention (5.5) on a scale of 1 to $7(1=$ very unlikely and $7=$ very likely to purchase) for Miltoniopsis in a green plastic pot for $\$ 19.95$. Miltoniopsis in a bamboo pot for \$29.95 (5.0) and Phalaenopsis in a black ceramic pot for $\$ 19.95$ (5.0) were the second and third most popular choices, respectively.

To our knowledge, only published research exists on environmental control of flowering of hybrids in the genus Miltonia, and preliminary data exists for Miltoniopsis. Matsui and Yoneda (1997) reported that growth and flowering of Miltonia cultivars were accelerated by artificially chilling plants at $15{ }^{\circ} \mathrm{C}$ under a 16-h photoperiod for $40 \mathrm{~d}$ in growth chambers. Preliminary results reported by Lopez et al. (2005) suggest that flowering of Miltoniopsis Augres 'Trinity' is promoted by cool temperatures, short photoperiods, or a combination of both.

To validate preliminary studies with Miltoniopsis Augres 'Trinity' (Lopez et al., 2005; Robinson, 2002), we performed experiments to determine how photoperiod and temperature influence flowering of two vegetatively propagated hybrids of Miltoniopsis. Our objectives were to determine 1) whether photoperiod before cooling at a range of temperatures enhances a vernalization response and 2) how durations of SD before vernalization and vernalization influence flowering of Miltoniopsis Augres 'Trinity' and Eastern Bay 'Russian'.

\section{Materials and Methods}

Plant material. Plants of the vegetatively propagated 'Trinity' clone of the hybrid Miltoniopsis Augres (Miltonia Pam-pam $\times$ Miltonia Alger) were transplanted into $8-$ and $10-\mathrm{cm}$ pots with a medium containing $80 \%$ fine-grade douglas fir bark and $20 \%$ medium-grade perlite (by volume) on 1 June 2001 and 22 May 2002 in a commercial greenhouse (Nurserymen's Exchange, Inc., Half Moon Bay, Calif.), respectively. Plants of the 'Russian' clone of the hybrid Miltoniopsis Eastern Bay (Miltonia Andy Easton $\times$ Miltonia Le Nez Point) were transplanted directly into $10-\mathrm{cm}$ pots on 16 June 2003. Plants were grown at about 25/14 ${ }^{\circ} \mathrm{C}$ day/night under natural photoperiods (lat. $37^{\circ} \mathrm{N}$ ) with an average photosynthetic photon flux $(P P F)$ of 160 to $240 \mu \mathrm{mol} \cdot \mathrm{m}^{-2} \cdot \mathrm{s}^{-1}$. Three hundred fifty of these 'Trinity' and 'Russian' plants were received in East Lansing, Mich., on 22 July 2002 and 22 Sept. 2003, respectively, and were subsequently grown in a glass-glazed greenhouse at a constant temperature of $\approx 20$ to $23{ }^{\circ} \mathrm{C}$ until experiments began. The photoperiod was a constant $16 \mathrm{~h}$ (0600 to $2200 \mathrm{HR})$, consisting of natural daylengths (lat. $42^{\circ} \mathrm{N}$ ), with day-extension lighting from high-pressure sodium (HPS) lamps that delivered a supplemental $P P F$ of $\approx 50 \mu \mathrm{mol} \cdot \mathrm{m}^{-2} \cdot \mathrm{s}^{-1}$ at plant height [long day (LD) HPS]. Light transmission through the greenhouses was reduced by using a permanent woven shade curtain that reduced light by about $55 \%$ (OLS 50; Ludvig Svensson, Charlotte, N.C.) and by applying whitewash to the glass so that the maximum $P P F$ was $300 \mu \mathrm{mol} \cdot \mathrm{m}^{-2} \cdot \mathrm{s}^{-1}$.

Prevernalization photoperiod and vernalization experiment (Expt. 1). The experiment was replicated in time, and experimental treatments were identical between years unless otherwise noted. Two hundred plants of 
Table 1. Average daily temperature and light integral during prevernalization, vernalization, and forcing of Miltoniopsis Augres 'Trinity' and Miltoniopsis Eastern Bay 'Russian' (Expts. 2 and 3).

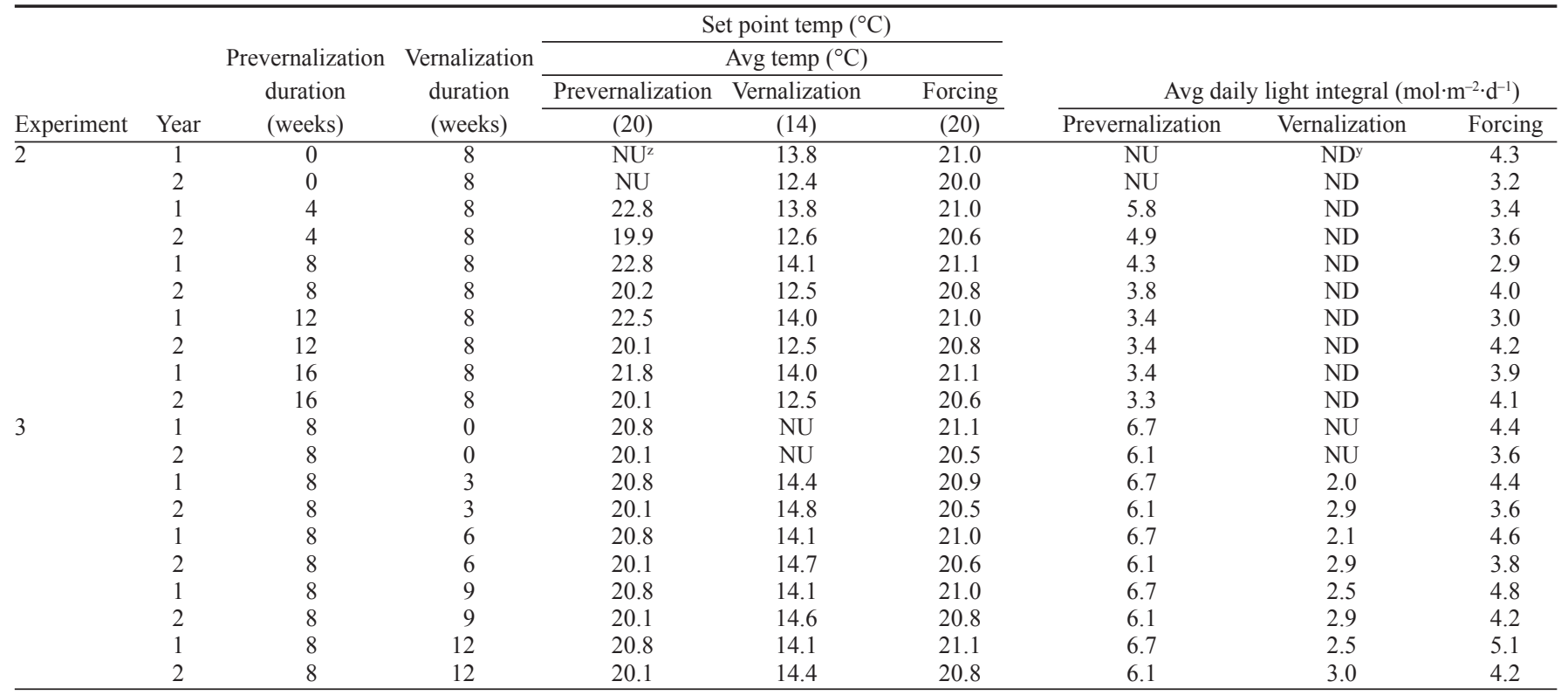

${ }^{2} \mathrm{NU}=$ treatment not used

${ }^{\mathrm{y}} \mathrm{ND}=$ no data collected.

Miltoniopsis Augres 'Trinity' were placed at $23{ }^{\circ} \mathrm{C}$ for 8 weeks under 9-h short days (SD) or 16-h LD (prevernalization photoperiods) beginning on 28 Aug. 2002 (Year 1) and 8 Dec. 2003 (Year 2). Photoperiods were created by retracting blackout cloth over plants from 1700 to $0800 \mathrm{HR}$. The 16-h photoperiod was created by light from incandescent lamps (delivering about $3 \mu \mathrm{mol} \cdot \mathrm{m}^{-2} \cdot \mathrm{s}^{-1}$ ) from 1655 to $2400 \mathrm{HR}$ (LD INC).

On 23 Oct. 2002 (Year 1) and 2 Feb. 2004 (Year 2), 20 plants of Miltoniopsis Augres 'Trinity' were transferred to greenhouse sections with temperature set points of 11 , $14,17,20$, and $23^{\circ} \mathrm{C}\left(8^{\circ} \mathrm{C}\right.$ was also used in Year 1). At each temperature, 10 plants were placed under SD and LD INC photoperiods for 8 weeks. Vapor pressure deficit during the temperature treatments was maintained at about $0.7 \mathrm{kPa}$ by the injection of water vapor as needed. After 8 weeks at the temperature treatments, plants were forced in a common greenhouse at $23{ }^{\circ} \mathrm{C}$ (Year 1 ) or $20{ }^{\circ} \mathrm{C}$ (Year 2) under LD HPS.

Prevernalization photoperiod experiment (Expt. 2). Miltoniopsis Augres 'Trinity' (Year 1) and Eastern Bay 'Russian' (Year 2) were grown at $20^{\circ} \mathrm{C}$ under SD or LD INC beginning on 26 July 2002 and 25 Sept. 2003, respectively, for $0,4,8,12$, or 16 weeks in a glass-glazed greenhouse. From 0800 to 1700 HR, HPS lamps provided a supplemental $P P F$ of $\approx 40 \mu \mathrm{mol} \cdot \mathrm{m}^{-2} \cdot \mathrm{s}^{-1}$ at plant level when the outdoor $P P F$ was $<140 \mu \mathrm{mol} \cdot \mathrm{m}^{-2} \cdot \mathrm{s}^{-1}$. The plants were then cooled for 8 weeks at $14^{\circ} \mathrm{C}$ under SD in a refrigerated growth chamber. The photoperiod during cooling was provided by a combination of cool-white fluorescent (VHOF96T12, Philips, Bloomfield, N.J.) and incandescent lamps from 0800 to $1700 \mathrm{HR}$ at $150 \mu \mathrm{mol} \cdot \mathrm{m}^{-2} \cdot \mathrm{s}^{-1}$. After the cooling treatment, plants were grown in the greenhouse at $20^{\circ} \mathrm{C}$ under LD HPS.
Vernalization duration experiment (Expt. 3). Miltoniopsis Augres 'Trinity' (Year 1) and Eastern Bay 'Russian' (Year 2) were grown for 8 weeks at $20^{\circ} \mathrm{C}$ under SD or LD INC beginning on 28 Aug. 2002 and 25 Sept. 2003, respectively. The plants were then cooled for 0 , $3,6,9$, or 12 weeks at $14^{\circ} \mathrm{C}$ under SD in a glassglazed greenhouse. After the vernalization treatments, plants were grown at $20^{\circ} \mathrm{C}$ under LDHPS in the greenhouse. Light intensity was controlled as previously described.

Greenhouse temperature and irradiance control. Greenhouse temperature set points were monitored and maintained by an environmental computer (Priva CD 750 Computer System,Vineland Station, Ontario) which controlled roof vents, exhaust fans, evaporative cooling pads, and heating as needed. Temperature on each bench was measured by a thermocouple $(0.127-\mathrm{mm}$ type E) in an aspirated chamber every $10 \mathrm{~s}$. Light intensity was measured by line quantum sensors (Apogee Instruments, Logan, Utah) located at plant height. Hourly averages were recorded by a CR-10 datalogger (Campbell Scientific, Logan, Utah). The average daily air temperature ( \pm standard deviation) and daily light integral (DLI) were $23.7 \pm 2.4^{\circ} \mathrm{C}$ and $3.2 \mathrm{~mol} \cdot \mathrm{m}^{-2} \cdot \mathrm{d}^{-1}$ during the prevernalization treatment of Expt. 1 . The actual average temperatures during vernalization were $8.9 \pm 1.8,11.6 \pm 1.9,14.2 \pm 0.8$, $17.2 \pm 1.0,19.9 \pm 0.6$, and $24.1 \pm 1.4{ }^{\circ} \mathrm{C}$, and the average DLI was $3.2 \mathrm{~mol} \cdot \mathrm{m}^{-2} \cdot \mathrm{d}^{-1}$. During forcing, the averages were $22.5 \pm 2.8^{\circ} \mathrm{C}$ and 3.8 $\mathrm{mol} \cdot \mathrm{m}^{-2} \cdot \mathrm{d}^{-1}$. Average daily air temperature and DLI were calculated for Expts. 2 and 3 from the beginning of the prevernalization photoperiod until the end of forcing (Table 1).

Plant culture. Plants in all three experiments were irrigated as necessary with reverse osmosis water supplemented with water-soluble fertilizer to provide the following $\left(\mathrm{mg} \cdot \mathrm{L}^{-1}\right)$ : $125 \mathrm{~N}, 12 \mathrm{P}, 100 \mathrm{~K}, 65 \mathrm{Ca}, 1.0 \mathrm{Fe}$ and $\mathrm{Cu}, 0.5$
Mn and Zn, 0.3 B, and 0.1 Mo (MSU Special, Greencare Fertilizers, Chicago, Ill.). In Year 2, Miltoniopsis Augres 'Trinity,' plants were transplanted into $10-\mathrm{cm}$ pots containing $66 \%$ medium-grade fir bark, 17\% long-fiber Canadian sphagnum peat, and $17 \%$ medium-grade perlite (by volume).

Data collection and analysis. The date at which the first inflorescence was visible without dissection (visible inflorescence, or VI) and the date that the first flower opened were recorded for each plant. Days to VI, days from VI to flower, days to flower, the percentage of plants that initiated or aborted an inflorescence, and flowering percentage were calculated for each treatment. The total number of VIs and the number of flower buds and flowers on the first VI were recorded for each plant. On the date of flowering, inflorescence length from emergence to the tip of the inflorescence was measured on the first VI. Each year, a completely randomized block design was used with ten plants randomly assigned to each treatment. Data were pooled for Year 1 and 2 of Expt. 1 for all measured characteristics. Data in Expt. 2 and 3 represent 1 year of data for each hybrid. Data were analyzed with SAS (SAS Institute, Cary, N.C.) mixed model procedure (PROC MIXED), and pairwise comparisons between treatments were performed using Tukey's honest significant difference test (HSD).

\section{Results}

Photoperiod and vernalization experiment (Expt. 1). The photoperiod before vernalization and vernalization temperature both significantly $(P \leq 0.05$ and $P \leq 0.001$, respectively) influenced the VI percentage of Miltoniopsis Augres 'Trinity' (Fig. 1). Plants exposed to 8 weeks of SD followed by 8 weeks of vernalization at 11 to $14{ }^{\circ} \mathrm{C}$ had the highest flowering percentage $(\geq 75 \%)$. Flower initiation was vari- 


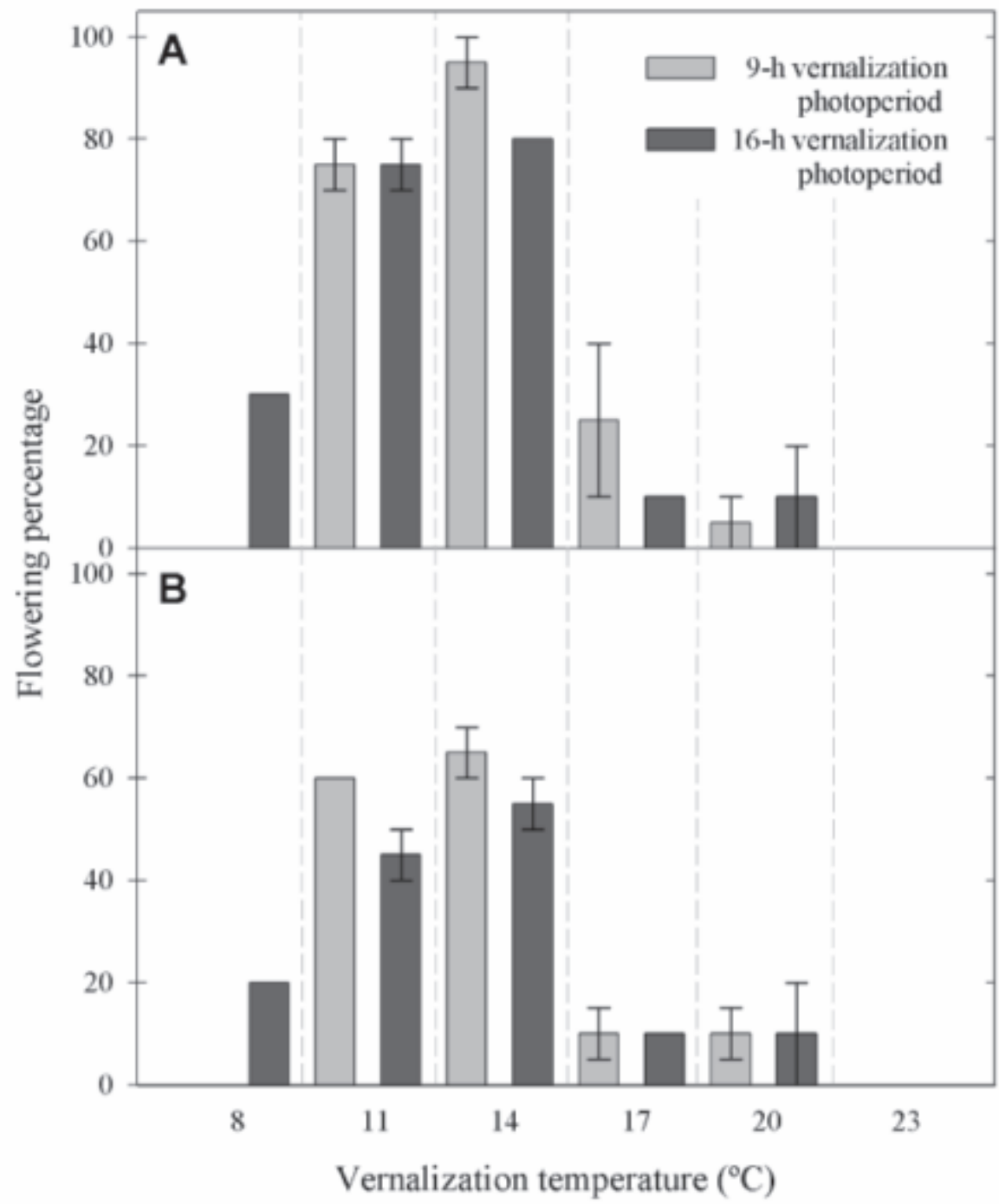

Fig. 1. Flowering percentage of Miltoniopsis Augres ‘Trinity' after a prevernalization photoperiod of $9 \mathrm{~h}$ (A) or $16 \mathrm{~h}\left(\right.$ B) for 8 weeks at $23{ }^{\circ} \mathrm{C}$ followed by 8 weeks at $8,11,14,17,20$, or $23{ }^{\circ} \mathrm{C}$ under a 9 - or 16-h photoperiod. Plants were subsequently grown at $23^{\circ} \mathrm{C}$ under a 16 -h photoperiod. Data were pooled for Years 1 and $2(n=20)$. The effects of prevernalization photoperiod and vernalization photoperiod and temperature on flowering percentages were analyzed using a binomial distribution with logit transformation. Vertical bars represent the standard error of the mean.

able when vernalization temperatures were $\geq 17$ ${ }^{\circ} \mathrm{C}$, and inflorescence abortion was observed. In general, flower induction was greatest when plants were exposed to SD before vernalization treatments. Average time to VI from the start of the prevernalization photoperiod was $166 \pm$ $36 \mathrm{~d}$ ( \pm standard deviation), and time to flower from VI was $73 \pm 5 \mathrm{~d}$ across all treatments (data not presented). Flowering plants had a similar inflorescence count, flower number, and inflorescence height, and the means were $1.6,4.6$, and $27.9 \mathrm{~cm}$, respectively (data not presented).

Prevernalization duration experiment (Expt. 2). Flowering of Miltoniopsis Augres 'Trinity' was most complete $(\geq 90 \%)$ and uniform when plants were exposed to 4 or 8 weeks of a prevernalization SD photoperiod at $20{ }^{\circ} \mathrm{C}$ before vernalization at $14{ }^{\circ} \mathrm{C}$ (Table 2). At least $80 \%$ of Miltoniopsis Eastern Bay 'Russian' plants flowered in all prevernalization treatments. There was a linear or quadratic increase in time to VI as the prevernalization to 9 weeks. However, time to flower from the start of forcing decreased as vernalization duration increased for both hybrids. For example, Augres 'Trinity' and Eastern Bay 'Russian' vernalized for 9 weeks reached VI an average of 99 or 48 d earlier than plants not vernalized. Time to flower from VI at $20{ }^{\circ} \mathrm{C}$ was similar for all treatments and averaged $76 \pm 5$ and 56 $\pm 7 \mathrm{~d}$, respectively, for Augres 'Trinity' and Eastern Bay 'Russian' (data not presented). Flowering plants of Eastern Bay 'Russian' had a similar flower bud number among all vernalization treatments, but flower number of Augres 'Trinity' increased as vernalization duration increased to approximately 9 weeks (Table 3). The number of inflorescences per plant and the height of the first VI were not influenced by prevernalization photoperiod or vernalization duration, and the means were 1.5 and $20.8 \mathrm{~cm}$ and 1.8 and $21.6 \mathrm{~cm}$ for Augres 'Trinity' and Easter Bay 'Russian,' respectively (data not presented).

\section{Discussion}

In Expt. 1, the most complete, rapid, and uniform flowering of Miltoniopsis Augres 'Trinity' occurred when plants were placed under SD for 8 weeks and then vernalized under $\mathrm{SD}$ at 11 to $14{ }^{\circ} \mathrm{C}$ for 8 weeks. The duration of $\mathrm{SD}$ before cooling that was required for most rapid flowering was determined in Expt. 2, in which 4 to 8 weeks of SD elicited the highest flowering percentage and most rapid flowering. Results from Expt. 3 showed that 9 to 12 weeks of cooling at $14^{\circ} \mathrm{C}$ was required and that plants exposed to LD before cooling often had a lower flowering percentage. These results are supported by Robinson (2002), in which $90 \%$ to $100 \%$ of Miltoniopsis Augres ‘Trinity'flowered when placed in environmental chambers with constant temperatures of $14^{\circ} \mathrm{C}$ under a 9-h SD. However, a moderate percentage of Augres 'Trinity' plants flowered in nearly all treatments, indicating that flowering is not highly controlled by environmental conditions.

Miltoniopsis Eastern Bay 'Russian' flowered under a wider range of environmental conditions than Augres 'Trinity', but both hybrids flowered earliest when exposed to a similar sequence of SD followed by exposure to a cool temperature (i.e., $14^{\circ} \mathrm{C}$ ). Flowering in response to low temperature alone or in combination with SD has been reported in other orchid genera native to Central and South America. For example, flowering of Zygopetalum Redvale 'Fire Kiss' was most complete when plants were grown under SD and then cooled at 11 to $14^{\circ} \mathrm{C}$ for approximately 8 weeks (Lopez et al., 2003). In Odontioda George McMahon 'Fortuna' and Odontioda Lovely Penguin 'Emperor', the percentage of plants that initiated an inflorescence was greatest $(\geq 90 \%)$ when plants were grown at 14 and $17^{\circ} \mathrm{C}$ (Blanchard, 2005). The importance of SD before cooling has also been observed in other epiphytes such as Hatiora, in which plants exposed to LD before vernalization ( 7.5 to $12.5^{\circ} \mathrm{C}$ for 4 weeks) flowered poorly. However, when Hatiora was provided with SD before vernalization, the flowering percentage 
Table 2. The effect of prevernalization photoperiod and duration on inflorescence initiation percentage (including aborted inflorescences), and days to visible inflorescence (VI) from start of prevernalization (PV) treatment and the start of forcing of Miltoniopsis Augres 'Trinity' and Eastern Bay 'Russian' (Expt. 2). The PV photoperiod was 9 or $16 \mathrm{~h}$ and was delivered at $20^{\circ} \mathrm{C}$ for the indicated durations. Plants were then vernalized for 8 weeks at $14{ }^{\circ} \mathrm{C}$ under a 9 -h photoperiod and subsequently forced at $20^{\circ} \mathrm{C}$ under a 16 -h photoperiod.

\begin{tabular}{|c|c|c|c|c|c|c|c|}
\hline \multirow{2}{*}{$\begin{array}{l}\text { PV } \\
\text { photoperiod } \\
\text { (h) }\end{array}$} & \multirow{2}{*}{$\begin{array}{c}\text { PV } \\
\text { duration } \\
\text { (weeks) }\end{array}$} & \multicolumn{2}{|c|}{ Inflorescence initiation (\%) } & \multicolumn{2}{|c|}{ Days to VI from start of PV } & \multicolumn{2}{|c|}{ Days to VI from start of forcing } \\
\hline & & $\begin{array}{l}\text { Augres } \\
\text { 'Trinity' }\end{array}$ & $\begin{array}{l}\text { Eastern Bay } \\
\text { 'Russian' }\end{array}$ & $\begin{array}{l}\text { Augres } \\
\text { 'Trinity' }\end{array}$ & $\begin{array}{l}\text { Eastern Bay } \\
\text { 'Russian' }\end{array}$ & $\begin{array}{l}\text { Augres } \\
\text { 'Trinity' }\end{array}$ & $\begin{array}{l}\text { Eastern Bay } \\
\text { 'Russian' }\end{array}$ \\
\hline No photoperiod $^{2}$ & 0 & 60 & 100 & $154 \mathrm{bc}^{y}$ & $103 \mathrm{c}$ & 98 & $47 \mathrm{a}$ \\
\hline \multirow{2}{*}{9} & 12 & 80 & 100 & $203 a b c$ & $130 \mathrm{~b}$ & 63 & $-10^{x} \mathrm{~d}$ \\
\hline & 16 & 60 & 90 & $257 \mathrm{ab}$ & 193 a & 89 & $25 \mathrm{abc}$ \\
\hline \multirow[t]{2}{*}{16} & 4 & 40 & 90 & $145 \mathrm{bc}$ & $118 \mathrm{bc}$ & 61 & $34 \mathrm{ab}$ \\
\hline & 16 & 60 & 80 & $304 \mathrm{a}$ & $190 \mathrm{a}$ & 136 & $22 \mathrm{abc}$ \\
\hline \multicolumn{8}{|l|}{ Significance } \\
\hline \multicolumn{2}{|c|}{ Prevernalization photoperiod (PVP) } & & & NS & NS & NS & NS \\
\hline \multicolumn{2}{|c|}{ Prevernalization duration (PVD) } & & & $* * *$ & $* * *$ & NS & $* * *$ \\
\hline \multirow{2}{*}{\multicolumn{2}{|c|}{$\mathrm{P}_{\text {Linear }}$}} & & & *** & $* * *$ & NS & *** \\
\hline & & & & * & *** & * & $* * *$ \\
\hline \multicolumn{2}{|l|}{$P V P \times P V D$} & & & NS & NS & NS & NS \\
\hline
\end{tabular}

2Plants did not receive a photoperiod treatment before vernalization.

'Values within columns with the same letter are not significantly by Tukey's honest significant difference test at $P \leq 0.05$.

${ }^{\mathrm{x}} \mathrm{VI}$ occurred during the vernalization treatment.

NS,,$* * * *$ Nonsignificant or significant at $P \leq 0.05$ or 0.001 , respectively.

Table 3. The effect of vernalization duration on inflorescence initiation percentage (including aborted inflorescences), days to visible inflorescence (VI) from start of prevernalization (PV) treatment and the start of forcing, and flower count on the first VI of Miltoniopsis Augres 'Trinity' and Eastern Bay 'Russian' (Expt. 3). The PV photoperiod was 9- or 16-h and was delivered at $20^{\circ} \mathrm{C}$ for 8 weeks. Plants were then vernalized for the indicated durations at $14{ }^{\circ} \mathrm{C}$ under a 9-h photoperiod and subsequently forced at $20^{\circ} \mathrm{C}$ under a 16 -h photoperiod.

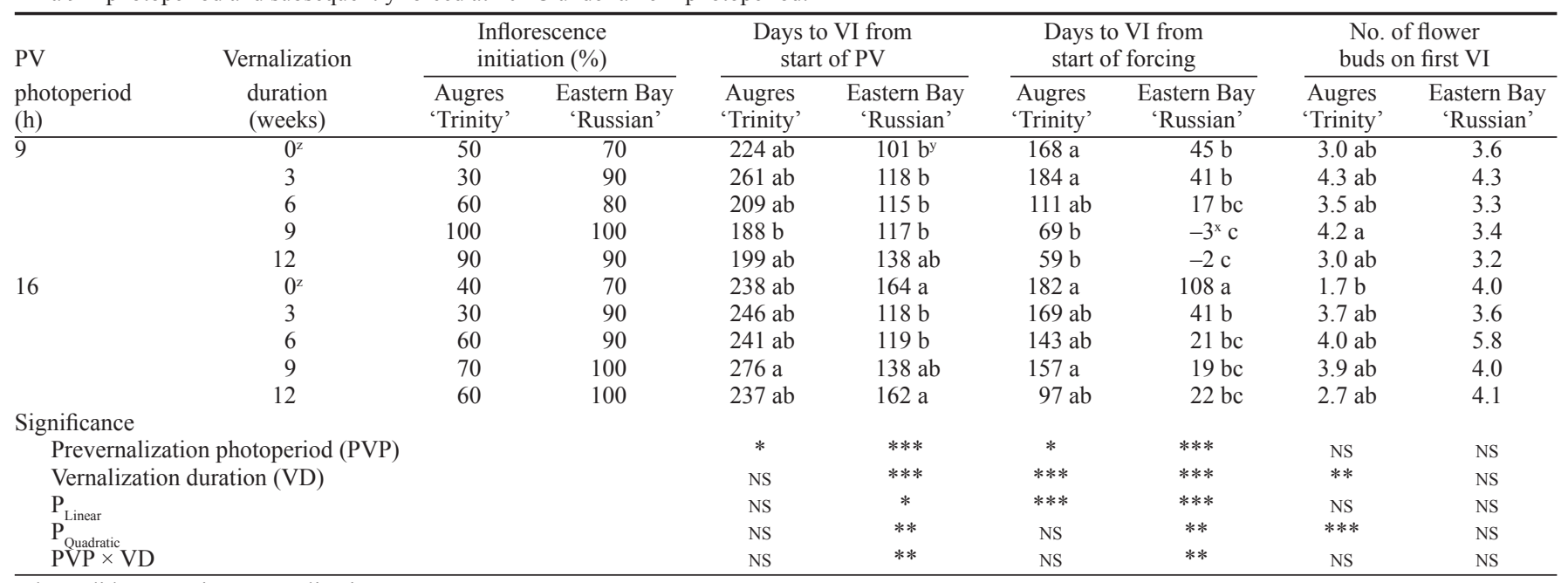

2Plants did not receive a vernalization treatment.

'Values within columns with the same letter are not significantly by Tukey's honest significant difference test at $P \leq 0.05$.

${ }^{x}$ VI were recorded during the vernalization treatment.

NS,***,**** Nonsignificant or significant at $P \leq 0.05,0.01$, or 0.001 , respectively.

increased to $93 \%$ to $100 \%$ (Rohwer, 2002).

We postulate that, similar to that of other flowering plants, a juvenile phase exists in Miltoniopsis and plants must reach a certain stage of growth before attaining the capacity to flower. Thus, sexual reproduction is delayed until plants reach a size sufficient to maintain the energetic demands of flowering and seed production. Lopez (2003) reported that pseudobulb maturity can significantly influence flower initiation and time to VI. Time to VI increased by $\approx 100$ d if the only inducible pseudobulb on a plant was immature. If an immature pseudobulb ( $\leq 6 \mathrm{~cm}$ in height) was placed in an inductive treatment, it was incapable of initiating flowers. However, immature pseudobulbs $\geq 7 \mathrm{~cm}$ had the capacity to initiate flowers, which could explain the variability in time to flowering that we observed within treatments and between experiments.

We have shown that flowering of a population of Miltoniopsis is promoted most by exposure to SD followed by exposure to a cool temperature (e.g., $14^{\circ} \mathrm{C}$ ), but some plants flowered without exposure to either or both treatments. This lack of a uniform flowering response and variability between hybrids can be problematic for greenhouse growers trying to produce flowering plants for specific holidays. Phalaenopsis orchids can be precisely scheduled into flower by maintaining vegetative growth at a high temperature (e.g., $28^{\circ} \mathrm{C}$ ) and inducing flowering at a lower temperature $\left(<25^{\circ} \mathrm{C}\right)$ (Sakanishi et al., 1980; Yoneda et al., 1992). However, Blanchard (2005) reported that hybrids of the same orchid genus respond differently to temperature. Phalaenopsis Miva Smartissimo $\times$ Canberra were reproductive at $26 / 26,26 / 14$, and $26 / 20^{\circ} \mathrm{C}$ (day/night), while no Brother Goldsmith '720' plants had initiated an inflorescence within 20 weeks. Conditions that inhibited flowering of Miltoniopsis the most (constant exposure to LD at $23^{\circ} \mathrm{C}$ ) elicited heat-stress symptoms in plants, and plant vigor gradually declined. Therefore, we have not identified environmental conditions that can strictly control transition from the vegetative to reproductive state. Additional research on the effects of temperature and photoperiod on plants of differing maturity is merited.

Nevertheless, the numerous positive attributes of Miltoniopsis merit its consideration as a potted flowering plant for winter and spring holidays (Christmas, Valentine's Day, 
Easter, and Mother's Day) when temperature in temperate climates in the northern hemisphere is not excessive for shipping and storage to preserve flower quality. Sales at these times would also facilitate production schedules for greenhouse growers in northern climates, in which growers could use the natural SD and cool temperatures of autumn and winter for flower induction.

\section{Literature Cited}

Baker, M.L. and C.O. Baker. 1993. Miltoniopsis culture II. Amer. Orchid Soc. Bul. 62:901-908.

Barendse, M. 2002. De sierteelt-toppers van 2001. Vakblad voor de Bloemisterij 2:24-27.

Behe, B.K, R.M. Walden, R.G. Lopez, and E.S. Runkle. 2003. Profile of potted orchid buyers in the Midwest. S. Nursery Assn. Res. Conf. Proc. 48:436-440.

Blanchard, M.G. 2005. Effects of temperature on growth and flowering of two Phalaenopsis and two Odontioda orchid hybrids. MS thesis. Mich.
State Univ., East Lansing.

Lopez, R.G. 2003. Effects of photoperiod and temperature on the growth and flowering of six orchid hybrids. MS thesis. Mich. State Univ., East Lansing.

Lopez, R.G. and E.S. Runkle. 2005. Environmental physiology of growth and flowering of orchids. HortScience 40:1969-1973.

Lopez, R.G., E.S. Runkle, and R.D. Heins. 2005. Flowering of the orchid Miltoniopsis Augres 'Trinity' is influenced by photoperiod and temperature. Acta Hort. 683:175-180.

Lopez, R.G., E.S. Runkle, R.D. Heins, and C.M. Whitman. 2003. Temperature and photoperiodic effects on growth and flowering of Zygopetalum Redvale 'Fire Kiss' orchid. Acta Hort. 624:155-162.

Matsui, N. and K. Yoneda. 1997. Effects of summer temperatures on growth and flowering of Miltonia. J. Jpn. Soc. Hort. Sci. 66:597-605.

Morrison, A. 2000. The illustrated encyclopedia of orchids. Timber Press, Portland, Ore.

Nash, N. 2003. Phalaenopsis primer: A beginner's guide to growing moth orchids. Orchids
72:906-913.

Robinson, K.A. 2002. Effects of temperature on the flower development rate and morphology of Phalaenopsis orchid. MS thesis. Mich. State Univ., East Lansing.

Rohwer, C.L. 2002. Flowering physiology of Hatiora. MS thesis. Mich. State Univ., East Lansing.

Sakanishi, Y., H. Imanishi, and G. Ishida. 1980. Effect of temperature on growth and flowering of Phalaenopsis amabilis. Bulletin of the University ofOsaka, Series B. Agr. Biol. Osaka (Prefecture) Daigaku. 32:1-9.

Sweet, H.R. 1978. The Miltonia complex in horticulture. Amer. Orchid Soc. Bul. 47:917-925.

U.S. Department of Agriculture. 2005. Floriculture crops 2004 summary. Agr. Stat. Board, Wash., D.C.

Yoneda, K., H. Momose, and S. Kubota. 1992. Comparison of flowering behavior between mature and premature plants of Phalaenopsis under different temperature conditions. Trop. Agr. 36:207-210. 